\title{
Development of a Derivative Design Process Considering Uncertainties from Low Fidelity Analysis Tools
}

\author{
Hyeong-Uk Park \\ Ph.D. Candidate, \\ Dept. of Aerospace Eng. \\ Ryerson University, \\ ainasul@gmail.com
}

\author{
Kamran Behdinan \\ Professor \& Chair \\ Dept. of Aerospace Eng. \\ Ryerson University, \\ kbehdina@ryerson.ca
}

\author{
Jae-Woo Lee \\ Professor, \\ Dept. of Aerospace \\ Information Eng. \\ Konkuk University, \\ jwlee@konkuk.ac.kr
}

\author{
Joon Chung \\ Associate Professor, \\ Dept. of Aerospace Eng. \\ Ryerson University, \\ j3chung@ryerson.ca
}

\begin{abstract}
A sensitivity analysis and an expert system have been applied to find the important design parameters for designing derivative aircraft subject to new design requirements. Additionally, the Reliability Based Design Optimization (RBDO) and Possibility Based Design Optimization (PBDO) methods are used to consider uncertainties on low fidelity analysis tools. This design process can used to reduce the time and cost for derivative design of engineering product by reducing the number of design variables. In this study, the process is applied to a conceptual design of light business jet aircraft.
\end{abstract}

\section{Introduction}

Many engineering product designs consider derivatives to reduce the life cycle cost and to increase the efficiency of an operation when it has new demand [1]. New customer demands produce the need on derivative designs in order to reduce manufacturing and operational cost. However, user requirements can change drastically which can ultimately lead to the inability to respond quickly to these change. Modern engineering products especially extremely complex systems such as aircraft, are strongly influenced the structural analysis, aerodynamic analysis, propulsion systems, avionics, and other disciplines [2]. The design of new commercial aircraft constitutes a massive investment over a long development period. Considering changing customer requirements necessitates an efficient and reliable design process for derivative design.

This research proposes an effective design process for derivative design to meet requirement changes from market demand. User requirements are analyzed and identified for quantity factors to select a target value. An expert system is implemented using a database of baseline designs and their derivatives to identify design trends for the new requirements [3]. In addition, a fuzzy logic function of the expert system defines the range of design parameters [4].
The selected design variables and their ranges are utilized in a global sensitivity analysis. It increases the efficiency and accuracy of the global sensitivity analysis. The result from the global sensitivity analysis determines the necessary design parameters to accomplish the desired result [5]. Decreasing the number of design variables and their range reduces the calculation time and cost for redesign. In addition, the sensitivity analysis for the uncertain responses of the disciplines identifies specific disciplines that are sensitive to uncertainties in order to increase the reliability of Multi-disciplinary Design Optimization (MDO) results. These techniques are applied to the proposed derivative design process to increase the reliability and efficiency of the derivative design process.

\section{Derivative Design}

Derivative designs for engineering products provide a cost effective design approach [2]. Many researchers have studied the design of aircraft derivatives using several different approaches. Firstly, research conducted by Richard Hibma (1981), Reinhold Birrenbach et al (2000), Robert B. Brown et al (2001), and Deepak Kumar et al (2006) identified the most important criteria for derivative designs using market requirement analysis, and considered altering constraints for the design problem [6, 7, 8, 9, and 10]. Secondly, Jonathan D. Yearsley et al (2008) researched the generation of a Pareto frontier in order to identify the candidate product family members $[11,12]$. Thirdly, Timothy W. Simpson et al (2002, 2006, and 2007) employed a derivative design using a Multi-Objective Genetic Algorithm. The product platform and its corresponding family of products were simultaneously optimized using a genetic algorithm while considering levels of platform [13, 14, and 15]. Furthermore, James Allison et al (2006), and Dongwook Lim and Dimitri N. Mavris (2007) researched other methods in order to design an aircraft family $[16,17]$.

The previous researchers considered the whole set of design variables simultaneously in order to design 
the baseline and its derivatives together. In addition, these researches considered derivatives on the conceptual design stage by assuming expected changes in product requirements. However, these assumptions may not accurately reflect future market changes. Furthermore, these frozen requirements for design would need to be redefined when considering derivatives for new requirements. The proposed derivative design process in this research obtains derivative designs as well as baseline product due to requirement changes while considering the selection of design variables. The efficiency and accuracy of the derivative design process can be enhanced by implementing these considerations.

\section{Proposed Process}

The proposed design process for derivative designs increases the computing efficiency and decreases the redesign cost. The expert system and the global sensitivity analysis methods identify the most necessary factors for the derivative design. Also, employment of the sensitivity analysis method and the uncertainty modeling methods increase the efficiency and accuracy of the MDO result by reducing of the number of design variables and disciplines. The whole procedure of derivative designs was shown in figure 1.

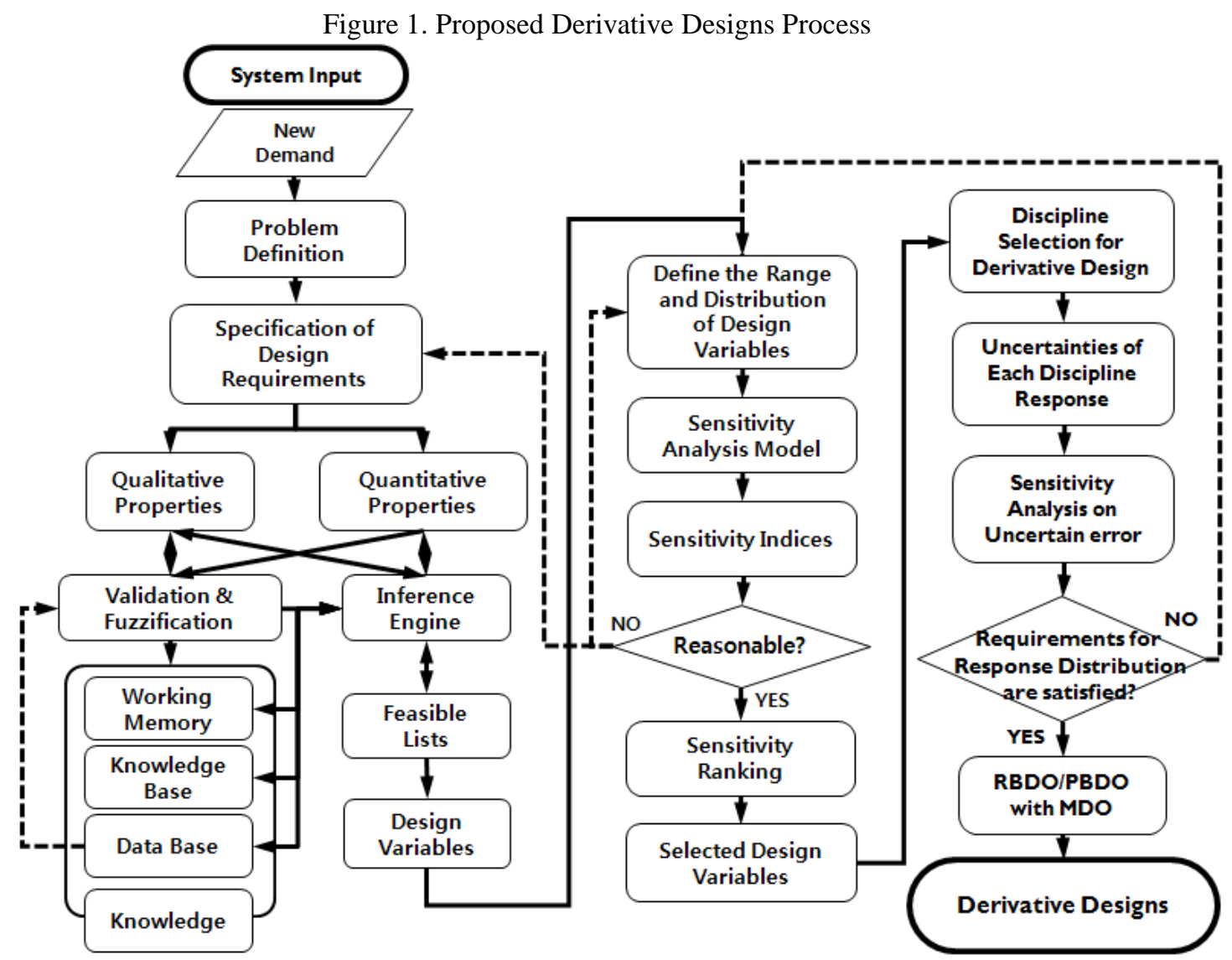

Table 1. Design Variables and Range for Fuzzy Function

\begin{tabular}{lccccc}
\hline & Very Low & Low & Medium & High & Very High \\
\hline Engine Thrust & 1500 & 2290 & 3080 & 3870 & 4660 \\
Wing Area & 178 & 264 & 350 & 436 & 522 \\
Vertical Tail Area & 46.8 & 47.975 & 49.15 & 50.325 & 51.5 \\
Horizontal Tail & 50 & 62.5 & 75 & 87.5 & 100 \\
Area & 13.875 & 17.552 & 21.229 & 24.906 & 28.583 \\
Cabin Length & 10.167 & 14.5628 & 18.9585 & 23.3543 & 27.75 \\
Wheel Base & 41.01 & 49.4725 & 57.935 & 66.3975 & 74.86 \\
W/S & 14.333 & 17.229 & 2.725 & 3 & 25.917 \\
W/T & 1248 & 1711 & 2174 & 23.021 & 3100 \\
Tail Span & 6 & 7 & 8 & 2637 & 10 \\
\hline \hline Range & & & & 9 & \\
Number of & & & & & \\
Passenger & & & & & \\
\hline
\end{tabular}




\subsection{Problem Definition and Expert System}

When a customer delivers new requirements, designers analyze the requirements and define the design problem. The analysis of new requirements for derivatives redefines the design requirements and identifies disciplines to consider the design derivatives of a baseline design. From the requirement analysis, a designer first defines the objectives of the derivative designs.

A Fuzzy Expert System is then used to identify the feasible list of design variables to satisfy the new demand. A database of baselines and their derivatives is used for the criteria from the requirement analysis and the inference engine in the Expert System. A study of the gathered data is necessary for the manufacturer to consider changes in the market requirements. The database is categorized by aircraft type and arranged by the parts that are considered to satisfy each additional requirement. It also displays the required parameters and their changes for satisfying the additional requirements. It provides guidance for selecting the design variables for local design changes. If additional requirements are not in the database, analysis modules and design parameters are added from the requirement analysis results. The first phase of the design process specifies the design variables needed to satisfy the new demands. These reduced design variables are utilized in the sensitivity analysis for the next phase.

In this research, 21 light business jet aircraft data were collected and a data base was derived [18, 19, $20,21,22,23,24]$. Using this database, rules from the expert system were derived. A fuzzy function, shown in Table 1, was used for input.

The expert system consists of the design variables, rules and results. For an input fuzzy function, these are normalized between 0 and 1 based on the database. 0 and 1 indicates the minimum and maximum values in the range respectively. Table 2 shows design variables and its normalized and real values. These parameters are from Cessna CJ1 aircraft $[18,20]$.

Table 2. Design variables and its value

\begin{tabular}{crc}
\hline Design variables & $\begin{array}{r}\text { Real } \\
\text { value }\end{array}$ & $\begin{array}{c}\text { Normalized } \\
\text { value }\end{array}$ \\
\hline Engine Thrust (lb) & 1900 & 0.13 \\
Wing Area (sq ft) & 240 & 0.18 \\
Cabin Length (ft) & 15.75 & 0.16 \\
Wheel Base (ft) & 15.38 & 0.30 \\
W/S (lb/sq.ft) & 44.17 & 0.09 \\
W/T (lb/lb st) & 2.79 & 0.62 \\
Tail Span (ft) & 18.50 & 0.36 \\
Range (NM) & 1248 & 0.04 \\
\hline
\end{tabular}

Table 3. Target values for derivative.

\begin{tabular}{crr}
\hline $\begin{array}{c}\text { Design } \\
\text { variables }\end{array}$ & \multicolumn{1}{c}{$\begin{array}{c}\text { Real } \\
\text { value }\end{array}$} & $\begin{array}{c}\text { Normalized } \\
\text { value }\end{array}$ \\
\hline Engine Thrust & 2500 & 0.32 \\
Wing Area & 277 & 0.29 \\
Cabin Length & 17.9 & 0.3 \\
Wheel Base & $13.21 \sim 19.25$ & $0.1 \sim 0.5$ \\
W/S & 51.0 & 0.3 \\
W/T & $2.49 \sim 2.94$ & $0.55 \sim 0.9$ \\
Tail Span & $19 \sim 23.55$ & $0.4 \sim 0.8$ \\
Range & 1557 & 0.2 \\
\hline
\end{tabular}

The target range of the derivative is $1557 \mathrm{NM}$ (the normalized value is 0.20 ). For this value, each of the design variables from the results of the expert system is given in Table 3 .

From these results, the ranges of each design variable were selected and are shown in Table 4.

Table 4. Range of design variables

\begin{tabular}{crrrr}
\hline \multirow{2}{*}{$\begin{array}{c}\text { Design } \\
\text { variables }\end{array}$} & \multicolumn{2}{c}{ Without } & \multicolumn{2}{c}{ With } \\
\cline { 2 - 5 } & \multicolumn{2}{c}{ Expert system } & \multicolumn{2}{c}{ Expert system } \\
\hline Boundary & $\begin{array}{c}\text { Upper } \\
\text { Boundary }\end{array}$ & $\begin{array}{c}\text { Lower } \\
\text { Boundary }\end{array}$ & $\begin{array}{c}\text { Upper } \\
\text { Boundary }\end{array}$ \\
\hline SA & 8 & 11 & 8.46 & 10.34 \\
TR & -1 & 5 & -1 & 1 \\
ARHT & 0.25 & 0.35 & 0.27 & 0.33 \\
ARVT & 5 & 7 & 5.472 & 6.688 \\
TRVT & 0.95 & 1.25 & 0.927 & 1.133 \\
TRHT & 0.4 & 0.65 & 0.495 & 0.605 \\
VC & 0.4 & 0.65 & 0.405 & 0.495 \\
ALT & 0.68 & 0.82 & 0.648 & 0.792 \\
THR & 17000 & 47000 & 43000 & 47000 \\
\hline
\end{tabular}

\subsection{Global Sensitivity Analysis}

Using the results of the previous stage, sensitivity analysis is carried out to identify which design variables are important for complying with the new design requirements. The sensitivity analysis is used for various applications such as ranking the respective parameters in order of their relative importance to the response, and assessing changes in the response due to parameter variations. The sensitivity analysis is used for selecting the important design variables for local design changes in an aircraft derivative design [25]. In this research, the LHS/PRCC method and the eFAST method are used for global sensitivity analysis.

The LHS/PRCC method is a sampling-based method that performs better than eFAST for a specific time point, reaching the same conclusions with much less computational cost. Moreover, it provides answers to questions such as how the output is affected if a specific parameter (linearly discounting the effects of the uncertainty over the rest of the parameters) is 
increased (or decreased). Thus PRCC can be informative on what parameters to target if it is wanted to achieve specific goals (e.g. control or regulatory mechanisms) [26].

The eFAST method is a variance-based method and it requires a greater number of model simulations. Also, when analyzing stochastic models, eFAST produces an artifact whereby aleatory variance is inappropriately partitioned to the total-order sensitivity index. eFAST, and all variance-based methods in general, indicate which parameter of uncertainty has the greatest impact on output variability. In other words, predictions will be strengthened if the uncertainty can be reduced to get better estimates on specific parameters of the model. This will also enhance any additional PRCC or sampling-based analysis because any regulatory or control strategy will be more reliable [26].

In this research, 489 cases were generated. The sensitivity analysis results of the LHS/PRCC method the eFAST results are shown in table 5 .

Table 5. Sensitivity analysis results of eFAST method

\begin{tabular}{ccccc}
\hline \multirow{2}{*}{$\begin{array}{c}\text { Design } \\
\text { variables }\end{array}$} & $\begin{array}{c}\text { WRCC value } \\
\text { expert } \\
\text { system }\end{array}$ & $\begin{array}{c}\text { Without } \\
\text { expert } \\
\text { system }\end{array}$ & $\begin{array}{c}\text { With } \\
\text { expert } \\
\text { system }\end{array}$ & $\begin{array}{c}\text { Without } \\
\text { expert } \\
\text { system }\end{array}$ \\
\hline $\begin{array}{c}\text { Aspect } \\
\text { ratio }\end{array}$ & -0.074 & -0.1905 & 0.547 & 1.4479 \\
\hline $\begin{array}{c}\text { Sweep } \\
\text { back } \\
\text { angle }\end{array}$ & -0.092 & 0.094 & 0.844 & 0.3519 \\
\hline $\begin{array}{c}\text { Taper } \\
\text { ratio }\end{array}$ & 0.048 & -0.058 & 0.229 & 0.3431 \\
\hline $\begin{array}{c}\text { Aspect } \\
\text { ratio of } \\
\text { H-tail }\end{array}$ & -0.021 & -0.103 & 0.044 & 0.0425 \\
\hline $\begin{array}{c}\text { Aspect } \\
\text { ratio of } \\
\text { V-tail }\end{array}$ & -0.04 & -0.11 & 0.016 & 0.0485 \\
\hline $\begin{array}{c}\text { Taper } \\
\text { ratio of } \\
\text { H-tail }\end{array}$ & 0.042 & -0.035 & 0.073 & 0.1251 \\
\hline $\begin{array}{c}\text { Taper } \\
\text { ratio of } \\
\text { V-tail }\end{array}$ & 0.027 & 0.2795 & 0.175 & 0.0496 \\
\hline $\begin{array}{c}\text { Cruising } \\
\text { speed }\end{array}$ & -0.49 & -0.7725 & 23.976 & 23.884 \\
\hline $\begin{array}{c}\text { Cruising } \\
\text { altitude }\end{array}$ & 0.415 & 0.2215 & 17.207 & 19.6187 \\
\hline \begin{tabular}{c} 
Thrust \\
\hline$y y y y$
\end{tabular} & -0.002 & 0.355 & 0.003 & 0.0506 \\
\hline
\end{tabular}

When the expert system is applied, aspect ratio, sweep back angle, main wing taper ratio, cruising speed and cruising altitude are selected. These selected design variables are used for the optimization method.

\subsection{Design optimization under uncertainties}

The Reliability-Based Design Optimization (RBDO) method and the Possibility-Based Design Optimization (PBDO) method were developed to consider the influence of uncertainties on a design optimization. The RBDO method is the prevailing approach in stochastic design optimization where the amount of input data is sufficient to create accurate input statistical distribution functions. When sufficient information of input data cannot be obtained, the probabilistic method cannot be used for reliability analysis and design optimization. For such cases, the PBDO method should be used for considering uncertainty in design optimization. PBDO uses a fuzzy function for modeling uncertain parameters and it is useful for cases which have insufficient data to generate the probability density function.

\subsubsection{Reliability Based Design Optimization}

The basic idea behind RBDO is employing numerical optimization algorithms in order to obtain optimal designs ensuring reliability [27]. When an optimization is performed without considering uncertainties, constraints that are active at the deterministic solution may induce a system failure. The reliable solution has a slightly higher function value than the deterministic optimization result, while satisfying targeted reliability levels in feasible design regions. In the RBDO method, the uncertainties are modeled using probability theory. The probability distributions of the random variables are obtained using statistical models. Defining uncertain variables as well as the failure modes are important to the implementation of RBDO. The probability of failure corresponding to a failure mode can be obtained or posed as a constraint in the optimization problem to obtain safer designs [28]. In system parameter design, the RBDO model can generally be defined as [29]

$$
\begin{gathered}
\text { minimize Cost }(d) \\
\text { subject to } P\left(G_{i}(X) \leq 0\right)-\Phi\left(-\beta_{t}\right) \leq 0, \\
i=1,2, \ldots, n p \\
d^{L} \leq d \leq d^{U}, d \in R^{n d v} \\
\text { and } X \in R^{n d v}
\end{gathered}
$$

The critical failure modes in the deterministic optimization are replaced with constraints on the probabilities of failure corresponding to each of the failure driven modes or with a single constraint on the system probability of failure. The reliability index, or the probability of failure corresponding to either a failure mode or a system, can be computed by performing a probabilistic reliability analysis [29].

\subsubsection{Possibility Based Design Optimization}


For uncertainty with insufficient information, possibility-based methods have been introduced in design optimization. When there is insufficient information for input data, the possibility-based method gives more conservative design results than the probabilistic design [30,31]. It can be a merit since a conservative optimum design is preferred when accurate statistical information is not available. There are two advantages in the fuzzy analysis compared to the probability analysis. First, the fuzzy input variables can be defined easier than the input random variables when there are not enough statistical data available. Secondly, extended fuzzy operations are much simpler than probability based methods especially when the number of variables is insufficient. The general formulation of PBDO was shown in below [30].

minimize Cost $(d)$

$$
\begin{gathered}
\text { subject to } \Pi\left(G_{i}(X)>0\right) \leq a_{t}, i=1,2, \cdots, n p \\
d^{L} \leq d \leq d^{U}
\end{gathered}
$$

\subsubsection{RBDO and PBDO for Aircraft Conceptual Design}

RBDO and PBDO algorithms were implemented to manage the errors associated with the traditional low fidelity analysis used in aircraft conceptual design. Error terms can be generated from comparing analysis results using empirical equations and a historical data base. These error terms were influenced on each constraint. RBDO and PBDO targets only active constraints, adjusting designs away from active constraints within the optimization scheme. In this research, approaching speed and take off field length are selected for constraints and these results of analysis module are compared with actual data of each aircraft. Cruise range of the aircraft is the objective function for the optimization problem. These errors are simulated PDF and fuzzy functions for RBDO and PBDO methods.

The error distribution of the approach speed has a mean value of 1.0043 , as well as variance and standard deviation of 0.0018 and 0.0423 respectively. In addition, the error distribution of the take off field length has a mean value of 0.9909 , variance of 0.0019 , and standard deviation of 0.0441 . The target reliability index level is $3 \sigma$. Table 6 shows the deterministic optimization, RBDO and PBDO results. From this data, the RBDO and PBDO results were found to have lower cruise range than the deterministic optimization (CO) result. These results lay on a feasible region when the constraints were adjusted to consider the uncertainties while also satisfying the target reliability index level. The error terms from each discipline were not the same since the comparison of information was different.
Table 6. Comparison of Optimization Results

\begin{tabular}{crrrr}
\hline Output & $\begin{array}{c}\text { Initial } \\
\text { value }\end{array}$ & $\begin{array}{c}\text { Deterministic } \\
\text { Optimization }\end{array}$ & RBDO & PBDO \\
\hline $\begin{array}{c}\text { Approaching } \\
\text { speed (kts) } \\
\text { Take off } \\
\text { field length } \\
\text { (ft) }\end{array}$ & 114.8 & 114.6 & 114.3 & 114.1 \\
$\begin{array}{c}\text { Cruise range } \\
\text { (NM) }\end{array}$ & 1758.5 & 3264.1 & 3276.6 & 3362.7 \\
\hline
\end{tabular}

\section{Conclusion and Future Work}

In this study, an expert system as well as sensitivity analysis methods were applied to select the design variables for an aircraft derivative design. This design process is helpful for decreasing redesign cost for developing derivatives of a baseline aircraft. Furthermore, the RBDO and PBDO methods were applied to increase the reliability of the results when it has uncertainties in the analysis module. The process developed in this study is applicable to other types of engineering products and may save a considerable amount of time and effort for derivative designs. In the future, the desirable use of tools for each design issue should be tested and specified while a more flexible process to meet various customer needs should be established to handle uncertainties.

\section{References}

[1] D. L. Robinson and M. F. Melary, "Large Airplane Derivative Development Methodology”, AIAA/AHS/ASEE Aircraft Design Systems and Operations Meeting, Colorado Springs, Colorado, October 14-16, 1985.

[2] R. E. Perez, J. Chung, and K. Behdinan. “Aircraft conceptual design using genetic algorithms”, AIAA Paper, 4938(8), 2000.

[3] G. Kidwell and M. Eskey, "Expert System and Their Use in Augmenting Design Optimization”, AIAA/AHS/ASEE Aircraft Design System and Operations Meeting, Oct. 1985.

[4] L. A. Zadeh, G. J. Klir, and B. Yuan, "Fuzzy sets, Fuzzy logic, and Fuzzy Systems”, World Scientific, 1996.

[5] C. Xu and G. Gertner, "Extending a global sensitivity analysis technique to models with correlated parameters”, Computational Statistics \& Data Analysis 51, 5579 - 5590, 2007.

[6] R. Hibma and D. Wegner, "The Evolution of a Strategic Bomber”, AlAA 1981 Annual Meeting and 
Technical Display, Long Beach, California, May 12-1 4, 1981.

[7] R. H. Fulford, “Airplane Criteria Process”, World Aviation Congress \& Exposition, Anaheim, CA, USA, October 1997.

[8] R. Birrenbach "Regional Aircraft Family Design", 2000 World Aviation Conference, San Diego, CA, October 10-12, 2000.

[9] R. B. Brown and J. M. Swihart, "A New Family of Passenger Friendly Commercial Air Transports”, 39th AIAA Aerospace Sciences, Meeting \& Exhibit, Reno, NV, 8-11 January 2001.

[10] D. Kumar, W. Chen, and T. W. Simpson, “A Market-Driven Approach to the Design of PlatformBased Product Families”, 11th AIAA/ISSMO Multidisciplinary Analysis and Optimization Conference, Portsmouth, Virginia, 6 - 8 September 2006.

[11] J. D. Yearsley and C. A. Mattson, "Product Family Design using a Smart Pareto Filter”, 46th AIAA Aerospace Sciences Meeting and Exhibit, Reno, Nevada, 7 - 10 January 2008.

[12] J. D. Yearsley, and C. A. Mattson, "Interactive Design of Combined Scale-based and Module-based Product Family Platforms”, 12th AIAA/ISSMO Multidisciplinary Analysis and Optimization Conference, Victoria, British Columbia Canada, 10 - 12 September 2008.

[13] T. Simpson and B. D’Souza, “Assessing Variable Levels of Platform Commonality Within A Product Family Using A Multiobjective Genetic Algorithm”, 9th AIAA/ISSMO Symposium on Multidisciplinary Analysis and Optimization, Atlanta, Georgia, 4-6 September 2002.

[14] S. Valliyappan, and T. W. Simpson, "Exploring Visualization Strategies to Support Product Family Design Optimization”, 11th AIAA/ISSMO Multidisciplinary Analysis and Optimization Conference, Portsmouth, Virginia, 6 - 8 September 2006.

[15] A. Khajavirad, J. J. Michalek, and T. W. Simpson, "A Decomposed Genetic Algorithm for Solving the Joint Product Family Optimization Problem”, 48th AIAA/ASME/ASCE/AHS/ASC Structures, Structural Dynamics, and Materials Conference, Honolulu, Hawaii, 23 - 26 April 2007.

[16] D. Lim and D. N. Mavris. "An Approach to Evolutionary Aircraft Design for Growth Potential”, 7th AIAA Aviation Technology, Integration and Operations Conference (ATIO), Belfast, Northern Ireland, 18 - 20 September 2007.
[17] J. Allison, B. Roth, M. Kokkolaras, I. Kroo and P. Y. Papalambros, "Aircraft Family Design Using Decomposition-based Methods", 11th AIAA/ISSMO

Multidisciplinary Analysis and Optimization

Conference, Portsmouth, Virginia, 6 8 September 2006.

[18] JANE'S ALL THE WORLD'S AIRCRAFT 2004 2005.

[19] http://www.aerospace.bombardier.com

[20] www.cessna.com

[21] www.embraer.com

[22] www.grob-aircraft.eu

[23] www.hawkerbeechcraft.com

[24] http://www.sj30jet.com/

[25] A. Saltelli, K. Chan, and E.M. Scott, editors. Sensitivity analysis. Wiley Series in Probability and Statistics. Wiley, 2000

[26] S. Marino, I. B. Hogue, C. J. Ray, and D. E. Kirschner, "A methodology for performing global uncertainty and sensitivity analysis in systems biology", Journal of Theoretical Biology 254, 2008, 178- 196

[27] L. Du, K.K. Choi, B.D. Youn and D. Gorsich, "Possibility-Based Design Optimization Method for Design Problems with both Statistical and Fuzzy Input Data”, Journal of Mechanical Design, Vol. 128, No. 928, Jul. 2006, pp. 928-936.

[28] H. Agarwal, Reliability Based Design Optimization : Formulations and Methodologies, $\mathrm{PhD}$ Thesis, University of Notre Dame, 2004.

[29] B.D. Youn, K.K. Choi and Y.H. Park, "Hybrid analysis method for reliability-based design optimization. Journal of Mechanical Design”. ASME Vol. 125, No.2, 2003, pp. 221-232.

[30] K.K. Choi and B.D. Youn, "Hybrid analysis method for reliability-based design optimization”. 27th ASME Design Automation Conference, DETC2001/DAC-21044, Pittsburgh, PA, 2001.

[31] M. Savoia, "Structural Reliability Analysis through Fuzzy Number Approach, with Application to Stability", Computers \& Structures, Vol. 80, Issue 12, May 2002, pp. 1087-1102. 